\title{
THE RELATION BETWEEN MICROSTRUCTURE COMPOSITION AND FATIGUE PROPERTIES OF ADI
}

The presented work deals with a high-strength variant of nodular cast iron, so-called ADI (austempered ductile iron). This material ranks among prospective structural materials and is more and more applied in all important branches of machine industry. Recently it has even been applied to castings for cyclically loaded components, i.e. gears and traversing wheels, crankshafts of motor-cars, vans and trucks, swivel pins, rail brakes, pressure pipes in oil industry etc. The microstructure composition of an ADI matrix consists especially of bainitic ferrite and stabilized austenite. However, in dependence on transformation dwell some amount of martensite can appear as well.

In this work the relation between mechanical properties and microstructure composition of the matrix mixture was studied in detail for the case of ADI transformed at $380^{\circ} \mathrm{C}$, with emphasis on fatigue properties.

\section{Introduction}

Austempered ductile iron used in an increasing measure for various cyclically loaded components $[1,2]$ is obtained by isothermal heat treatment of nodular cast iron. This way of heat treatment includes austenitization, isothermal transformation and final cooling usually in water. Heat treatment conditions influence the microstructure and mechanical properties of ADI differently: whereas the austenitization conditions (at usual temperatures in the range of 850 to $900{ }^{\circ} \mathrm{C}$ and typical dwell from 1 to 3 hours) play only a marginal role, the conditions of isothermal transformation (i.e. temperature and the length of isothermal transformation dwell) influence the matrix microstructure composition and, consequently, mechanical properties of ADI substantially [3, 4].

This work is focused on the relation between the matrix mixture composition and mechanical properties of ADI in dependence on isothermal transformation dwell. For the study an ADI obtained by isothermal transformation at the temperature of $380{ }^{\circ} \mathrm{C}$ was chosen. For determining the relation between the matrix mixture composition and mechanical properties of ADI the transformation dwells in the range of 2 to 540 minutes were used.

\section{Experimental material and techniques}

For the study an unalloyed nodular cast iron with chemical composition 3.56 wt. \% C, 2.24 wt. \% Si, 0.25 wt. \% Mn, 0.02 wt. \% P, 0.004 wt. \% S and 0.054 wt. \% Mg was selected.

Cylindrical testing bars for static tensile tests (with the initial diameter of $6 \mathrm{~mm}$ and gauge length of $30 \mathrm{~mm}$ ) and for fatigue tests (with the initial diameter of $7 \mathrm{~mm}$ and effective length of $10 \mathrm{~mm}$ ) were made from this material. Isothermal heat treatment was per- formed in the following steps: austenitization took 1 hour in $\mathrm{NaCl}$ salt bath at the temperature of $900{ }^{\circ} \mathrm{C}$, isothermal transformation was performed at the temperature of $380{ }^{\circ} \mathrm{C}$ in AS 140 salt bath, final cooling was done in water. For studying the relation between the obtained matrix mixture composition and mechanical properties of ADI the isothermal dwells of 2, 5, 10, 25, 60, 120, 270 and 540 minutes were used.

For the microstructure evaluation, the metallographic cuts were prepared using the front faces of screw heads. Etched and not etched microstructures were observed by an OLYMPUS GX 71 light microscope with an Olympus DP 11 digital camera. The content of stabilized austenite and the analysis of graphite nodules were determined by an image analysis using LUCIA software of the Laboratory Imaging Company and ACC software of the SOFO Company.

The tensile tests were performed at the usual room temperature (i.e. 20 to $25^{\circ} \mathrm{C}$ ) on the testing device TIRATEST 2300 with a force range of $100 \mathrm{kN}$. The crosshead speed was $2 \mathrm{~mm} / \mathrm{min}$ corresponding to the loading strain rate of $10^{-3} \mathrm{~s}^{-1}$. Fatigue tests were performed at the room temperature as well, at symmetrical loading cycle, using an AMSLER 10 FHP 1478 high-frequency resonance pulsator at the test frequency of $201 \mathrm{~Hz}$. Each of S-N curves was determined by the tests of 12 to 15 test bars. For the data regression by the least square method, the three-parametrical non-linear function (1) proposed by Stromeyer and recommended by Weibull [5] was used

$$
\sigma(N)=a N^{b}+\sigma_{\infty},
$$

where as $\sigma$ stress amplitude can be considered, $a, b$, and are parameters of the regression curve, and $N$ is the number of cycles to the fracture.

\footnotetext{
* Klára Hanzlíková ${ }^{1}$, Stanislav Věchet ${ }^{1}$ and Jan Kohout ${ }^{2}$

${ }^{1}$ Institute of Materials Engineering, Faculty of Mechanical Engineering, Brno University of Technology, Technická St 2, CZ-616 69 Brno, Czech Republic ${ }^{2}$ Department of Mathematics and Physics, Military Technology Faculty, University of Defence, Kounicova St 65, CZ-612 00 Brno, Czech Republic
} 


\section{Results}

The determined content of microstructure components, average values of static mechanical characteristics and fatigue limits for a reference number to the failure $N_{C}=10^{7}$ are presented in Table 1 for all the transformation dwells.

Static mechanical properties, fatigue limits, fatigue

Table 1 ratio and content of stabilized austenite or martensite (if any) of ADI transformed at $380{ }^{\circ} \mathrm{C}$ in dependence on transformation dwell.

\begin{tabular}{|c|c|c|c|c|c|c|c|}
\hline $\begin{array}{c}\tau_{t} \\
{[\mathrm{~min}]}\end{array}$ & $\begin{array}{c}R_{P} 0.2 \\
{[\mathrm{MPa}]}\end{array}$ & $\begin{array}{c}R_{m} \\
{[\mathrm{MPa}]}\end{array}$ & $\begin{array}{c}A_{5} \\
{[\%]}\end{array}$ & $\begin{array}{c}\delta_{C} \\
{[\mathrm{MPa}]}\end{array}$ & $\begin{array}{c}\delta_{C} / R_{m} \\
{[-]}\end{array}$ & $\begin{array}{c}A S \\
{[\%]}\end{array}$ & $\begin{array}{c}M \\
{[\%]}\end{array}$ \\
\hline 2 & - & 138 & 0.1 & - & - & 18.3 & 66.8 \\
\hline 5 & 562 & 698 & 0.3 & - & - & 28.5 & 34.3 \\
\hline 10 & 739 & 885 & 0.6 & - & - & 31.6 & 4.8 \\
\hline 25 & 773 & 1003 & 2.7 & 226 & 0.225 & 33.8 & 0 \\
\hline 60 & 830 & 1051 & 5.2 & 249 & 0.236 & 34.8 & 0 \\
\hline 120 & 853 & 1040 & 4.8 & 235 & 0.225 & 31.9 & 0 \\
\hline 270 & 872 & 1091 & 4.6 & 234 & 0.214 & 25.4 & 0 \\
\hline 540 & 899 & 1109 & 2.3 & - & - & 17.7 & 0 \\
\hline
\end{tabular}

As Table 1 and Fig. 1 show, the composition of the microstructure mixture in the matrix of ADI transformed at $380{ }^{\circ} \mathrm{C}$ is substantially influenced by the isothermal transformation dwell. The microstructure consists especially of bainitic ferrite and stabilized austenite. However, for short transformation dwells also some amount of martensite appears. In the case of the shortest dwell, i.e. 2 minutes, it is even a dominant structural component (see Figs 1, 2).

During the transformation of austenite into bainitic ferrite, the surrounding non-transformed austenite is being enriched by carbon, which increases its stability. It leads to a gradual increase in the amount of this phase in the matrix with an increasing transformation dwell, which is to the detriment of martensite creation. For the transformation dwell of 25 minutes the stability of nontransformed austenite is sufficient and so the martenzitic transformation during subsequent cooling is wholly suppressed. Stabilized austenite reaches its maximum content for the transformation dwell of 60 minutes (Fig. 3). With further prolongation of the transformation dwell its amount starts to decrease and for the longest dwell only about half of the maximum content was determined in the matrix microstructure (Fig. 1). The results of the mechanical properties testing show that their values are substantially influenced by the isothermal transformation dwell (see Table 1 and Figs 4, 5, 6).

UTS values $\mathrm{Rm}$ and yield stress $R_{p} 0,2$ increase in the whole range of studied dwells and reach their maxima for the longest dwells (see Fig. 4). The dependence of elongation to the fracture $A_{5}$ on the transformation dwell is different. Its value increases at first and reaches its maximum for the transformation dwell of 60 minutes. When this dwell length is exceeded, the value of $A_{5}$ changes

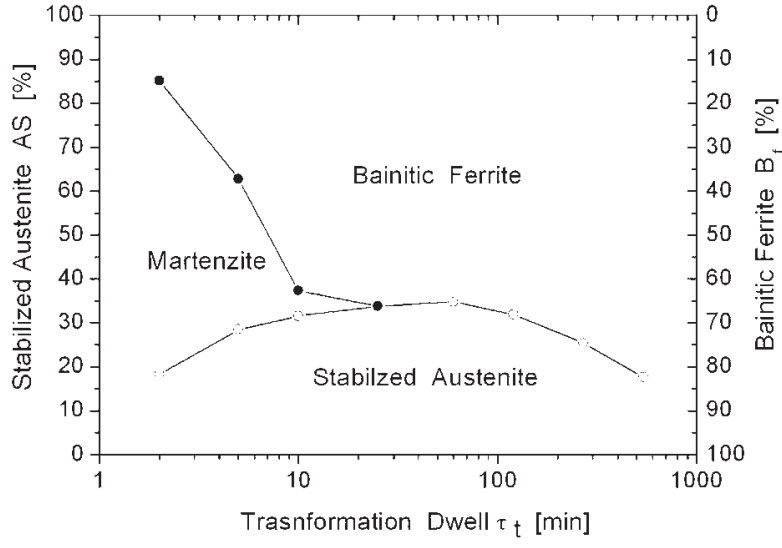

Fig. 1: The composition of the ADI microstructure in dependence on the transformation dwell.

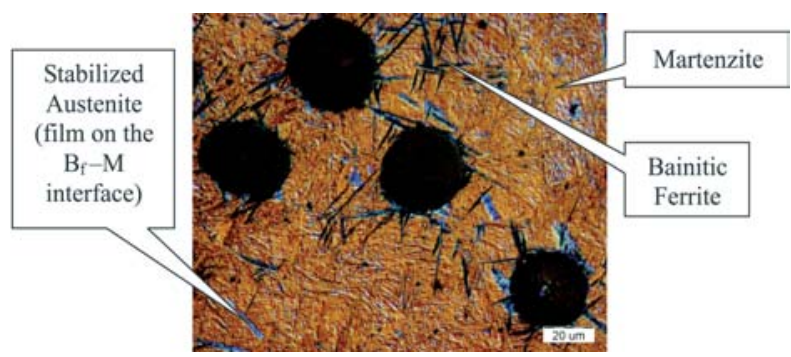

Fig. 2: The matrix microstructure of ADI for the transformation dwell of 2 minutes.

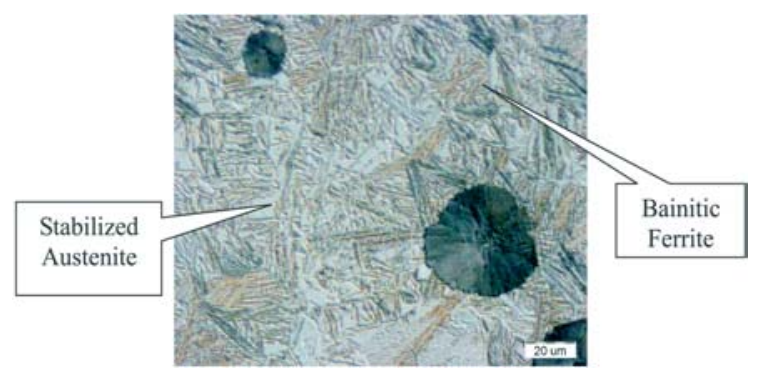

Fig. 3: The matrix microstructure of ADI for the transformation dwell of 60 minutes.

only slightly up to the dwell of 270 minutes, when it starts to decrease substantially (see Fig. 4).

In the previous work [4] as well as in the work [6], fatigue properties of nearly identical material changing with increasing transformation dwells were already studied. It was found out that the dependence of the fatigue limit $\sigma_{C}$ on the transformation dwell is similar to the dependence of $A_{5}$. In the range of short dwells, the value of the fatigue limit $\sigma_{C}$ gradually increases. After reaching its maximum, $\sigma_{C}$ decreases but still remains in the interval of sufficient values. Then the substantial decrease was observed till the longest dwells were achieved. Because of time-consuming 


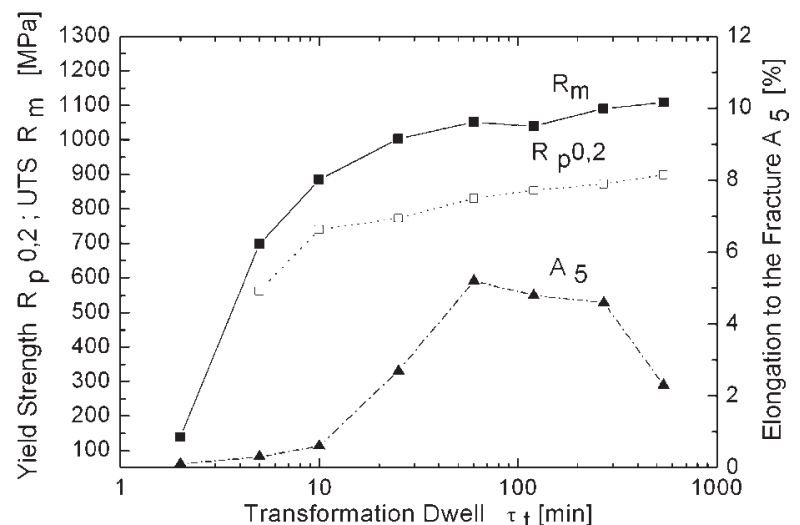

Fig. 4: Static mechanical properties of ADI in dependence on the transformation dwell.

fatigue tests, in this work only the range of transformation dwells from 25 to 270 minutes was tested, which was chosen pursuant to the previous studies. As Table 1 and Fig. 5 show, in the studied range of transformation dwells the value of fatigue limit $\sigma_{C}$ increases at first. Optimum fatigue properties were reached for the transformation dwell of 60 minutes, which is also evident in Fig. 6. After reaching its maximum, $\sigma_{C}$ slightly decreases but still remains in the range of sufficient values.

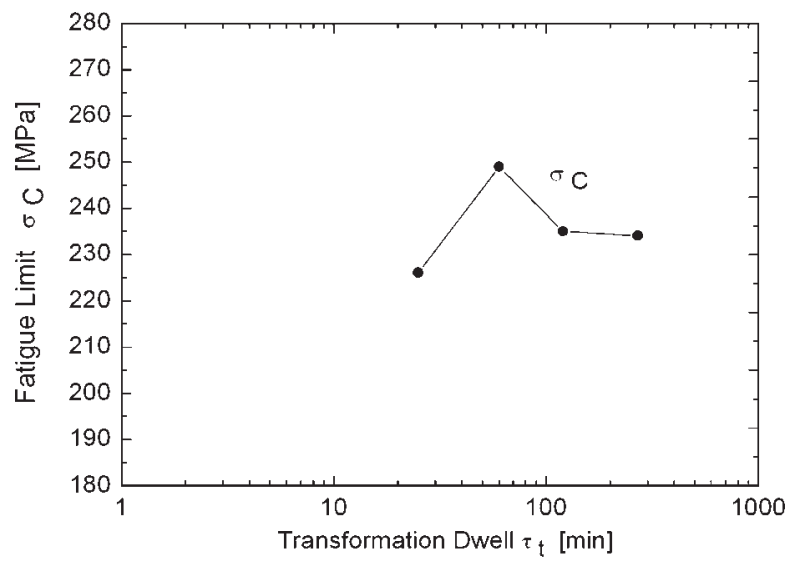

Fig. 5: The fatigue limit of studied ADI in dependence the transformation dwell.

Because of the similarity in the chemical composition of the studied material to the materials in previous studies, also the similarity in dependence of fatigue limit on the whole studied range of transformation dwells could be assumed. It follows from this similarity that in the range of 2 to 25 minutes fatigue limit will probably gradually increase with a transformation dwell prolongation and when the transformation dwell of 270 minutes is extended, the value of the fatigue limit will probably substantially decrease (approximately according to the Fig. 7).

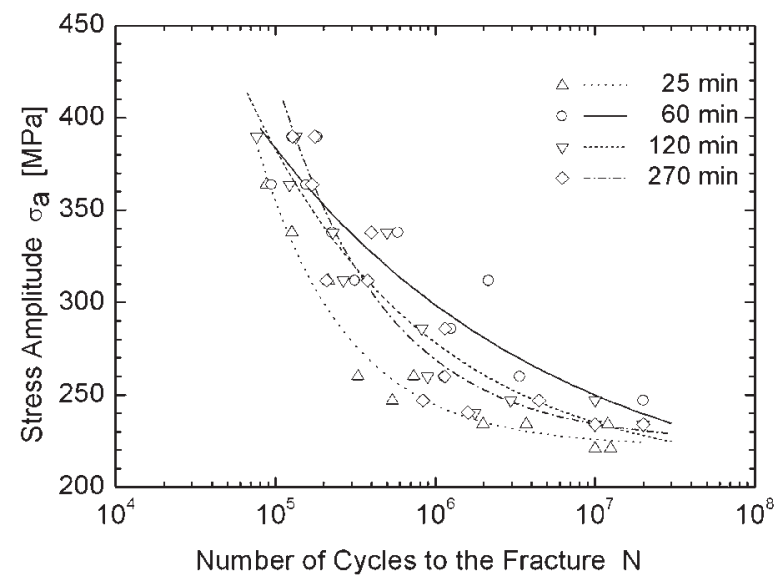

Fig. 6: The comparison of $S-N$ curves for studied transformation dwells

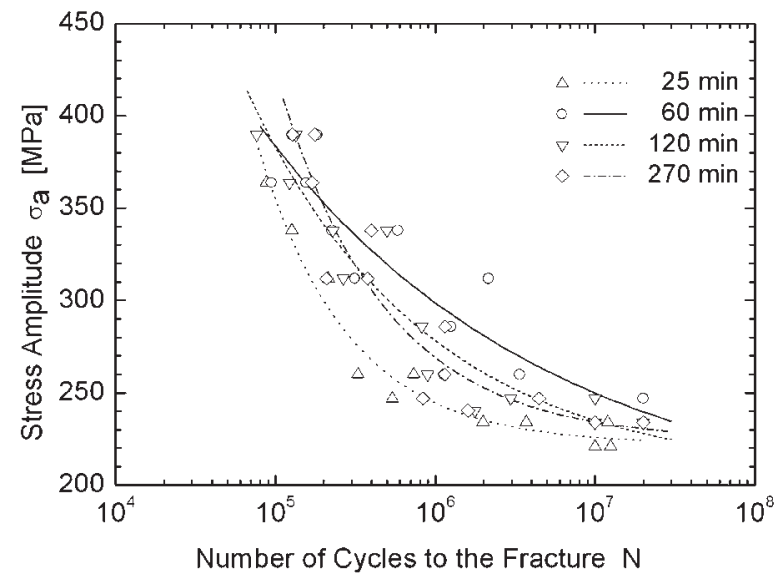

Fig. 7: The dependence of fatigue limit on the dwell at isothermal transformation of ADI obtained in previous study [4].

\section{Discussion}

Regarding the results of this study, it can be said that the values of mechanical properties depend on the structural matrix mixture. The ADI matrix consists especially of bainitic ferrite and stabilized austenite (Fig. 1). Bainitic ferrite is the carrier of strength in the ADI matrix, thus the UTS and yield stress reach their maxima when bainitic ferrite is a strongly prevalent structure component of the matrix (see dwells of 270 and 540 minutes in Fig. 4). Stabilized austenite is, on the contrary, the carrier of plasticity in the ADI matrix, thus the elongation to the fracture reaches its maximum for the transformation dwell when the matrix contains the maximum amount of stabilized austenite, i.e. for 60 minutes (see Fig. 8a). For longer dwells the elongation starts to decrease again as consequence of stabilized austenite decreasing due to its further transformation into bainitic ferrite.

The dependence of the fatigue limit on the transformation dwell coincides with the dependence of elongation to the fracture. 


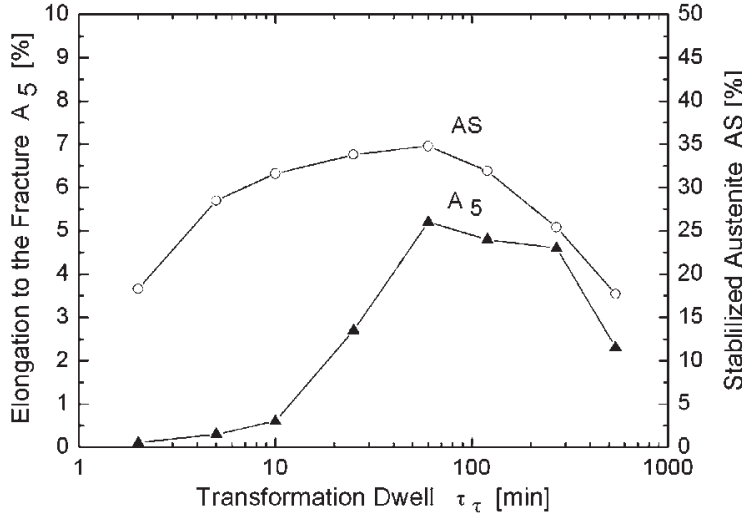

a)

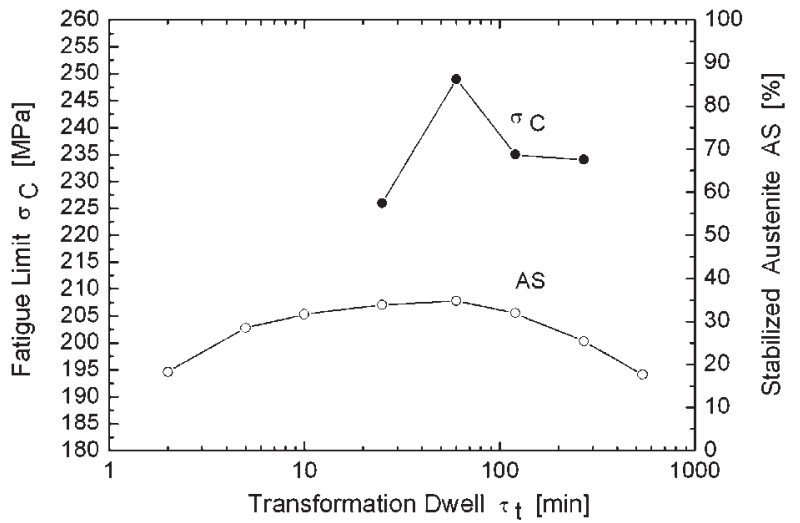

b)

Fig. 8: The comparison of dependences of elongation to the fracture (a) and of fatigue limit (b) with the amount of stabilized austenite on the transformation dwell.

Thus its maximum value is also reached when the matrix contains the maximum amount of stabilized austenite, i.e. for the transformation dwell of 60 minutes (Fig. 8b). A high level of the fatigue limit appears also when austenite content starts to decrease. The reason of this effect is probably an increasing deformability of bainitic ferrite with a transformation dwell prolongation.

In the case of short dwells, i.e. in the range of 2 to 25 minutes, lower values of strength, plasticity and fatigue limit are caused by the presence of martenzite in the ADI matrix, which is a brittle and very hard phase and cause premature cracks of the testing bars.

\section{Conclusions}

The microstructure matrix composition and, consequently, mechanical properties are very substantially influenced by the dwell at temperature of isothermal transformation. In the case of ADI obtained by isothermal transformation at temperature of $380{ }^{\circ} \mathrm{C}$, the optimum static mechanical properties were achieved for the transformation dwells in the range of 60 to 270 minutes. In the case of fatigue properties, the optimum range of transformation dwells is from 40 to 270 minutes approximately. To achieve the optimum combination of static and fatigue properties, the transformation dwell of 60 minutes should be used.

The results of the study show that in dependence on the transformation dwell, the ADI with high variety of mechanical properties can be obtained, thus ADI with combination of mechanical properties corresponding to a given application is possible to produce.

\section{Acknowledgement}

Financial supports of the Ministry of Defence of the Czech Republic within the research project MO0FVT0000404 are gratefully acknowledged.

\section{References:}

[1] HUGES, I. C. H.: Brit. Foundryman, vol. 74, 1981, p. 229

[2] KEOUCH, J. R.: Foundry Management and Technology, vol. 123, 1995, Nr. 11, p. 27

[3] VĚCHET, S., KOHOUT, J., HANZLÍKOVÁ, K.: Fatigue Properties of ADI in Dependence on Isothermal Transformation Dwell. Komunikácie, Žilinská univerzita v Žiline, 2/2004, p. 12-15. ISSN 1335-4205.

[4] VĚCHET, S., KOHOUT, J., HANZLÍKOVÁ, K.: Influence of Isothermal Dwell on Tensile and Fatigue Properties of Austempered Ductile Iron. Material Science Forum, volume 482/2005, ISSN 0255-5476, p. 371-374.

[5] WEIBULL, W.: Fatigue Testing and Analysis of Results. Pergamon Press, 1961.

[6] KOPAS, P., NOVÝ, F., BOKU゚VKA, O.: High-cycle Fatigue of High-strength Graphitic Cast Irons (in Slovak). In Proceedings of Letná škola únavy materiálov 2004, VII. ročník. Zuberec-Roháče, Slovenská republika 6.-10. 9. 2004. Žilinská Univerzita v Žilině, p. 198-206. ISBN 80-80-70-283-7. 